\title{
SERVIÇOS ECOSSISTÊMICOS EM LITORAIS URBANOS: O CASO DE FORTALEZA, CEARÁ, BRASIL
}

\author{
Jailson Cavalcante Lima ${ }^{(a)}$, Davis Pereira de Paula ${ }^{(b)}$
}

(a) Centro de Ciências e Tecnologia, Universidade Estadual do Ceará, jaillsonline@ gmail.com

(b) Centro de Ciências e Tecnologia, Universidade Estadual do Ceará, PROPGEO/UECE, MAG/UVA

davis.paula@uece.br

\section{Eixo: DINÂMICA E GESTÃO DE ZONAS COSTEIRAS}

\begin{abstract}
Resumo
Os ecossistemas litorâneos destacam-se pela grande disponibilidade de serviços ecossistêmicos indispensáveis ao bem-estar da sociedade e ao desenvolvimento econômico. As praias se sobressaem como principais pólos de interesse econômico voltado ao turismo. Diante disso, torna-se necessário fazer uma avaliação qualitativa dos serviços ecossistêmicos oferecidos pelas praias da cidade de Fortaleza, capital do estado do Ceará. Para uma avaliação qualitativa dos serviços ecossistêmicos foram realizadas visitas de campo ao longo de aproximadamente $30 \mathrm{~km}$ de linha de costa, durante o ano de 2016, onde estão inseridas 12 praias compartimentadas em dois segmentos do litoral (SE/NO e L/O) na qual foram atribuídos critérios para valoração dos serviços, que variaram de baixo (1), médio (2) e alto (3). A Praia da Sabiaguaba apresentou o maior escore dentre todas as demais, chegando ao total de 46, enquanto que a Praia do Mucuripe e Praia de Iracema apresentaram os menores valores, ambas, 26 escores.
\end{abstract}

Palavras chave: Serviços ecossistêmicos, praias, litoral, ecossistema.

\section{Introdução}

As regiões litorâneas abrigam uma diversidade de ecossistemas que funcionam como habitat biológico de inúmeras espécies, sendo que cada sistema natural apresenta um conjunto de potencialidades e limitações ao seu uso pela sociedade. $\mathrm{O}$ uso, direto ou não, que se faz de um geoambiente é determinado de serviço ecossistêmico. Por exemplo, algum uso do sistema para produção de alimentos já é considerado como um serviço. Andrade e Romeiro (2009) entendem que os serviços ecossistêmicos induzem à benefícios diretos e indiretos ao homem, com reflexos diretos no seu bem-estar.

Dentre os geoambientes de menor escala que integram os litorais urbanos é possível destacar as praias, que são feições formadas pela acumulação de sedimentos não consolidados através da ação da agitação marítima. De uma forma geral, as praias são espaços em que a sociedade utiliza para exercer atividades de lazer e recreação, ou seja, utilizam um serviço ecossistêmico prestado pelo geoambiente. Contudo, o uso indiscriminado e irracional pode, na maioria dos casos, conduzir a uma situação de insustentabilidade 


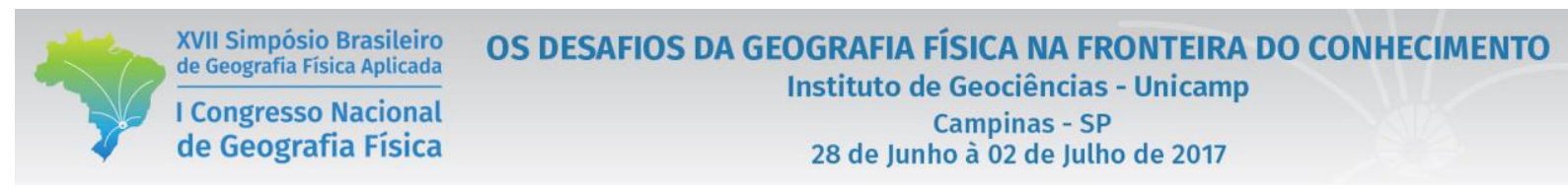

ambiental, em que os limiares da capacidade de carga do ambiente são ultrapassados, ocasionando a perda de qualidade ambiental do serviço ecossistêmico.

Deste modo, os ecossistemas litorâneos são indispensáveis ao bem-estar da sociedade, assim como ao desenvolvimento econômico, tornando-se oportuno uma gestão sustentável, que garanta a geração dos serviços. Assim, este estudo tem como objetivo fazer uma avaliação e valoração qualitativa dos serviços ecossistêmicos oferecidos pelo litoral da cidade de Fortaleza, capital do estado do Ceará, a partir da qualidade ambiental de suas praias.

\section{Materiais e métodos}

Para uma avaliação qualitativa dos serviços ecossistêmicos foram feitas observações a partir de imagens de satélites e realizadas visitas de campo ao longo de aproximadamente $30 \mathrm{~km}$ de linha de costa, durante o ano de 2016, onde estão inseridas 12 praias arenosas urbanas, que foram compartimentadas em dois segmentos: o litoral SE/NO, com as praias de Abreulândia, Sabiaguaba, Caça e Pesca, Praia do Futuro, e Serviluz, e o L/O, com as praias do Mucuripe, Náutico, Meireles, Iracema, Leste-Oeste, Pirambu e Barra do Ceará (Figura 1).

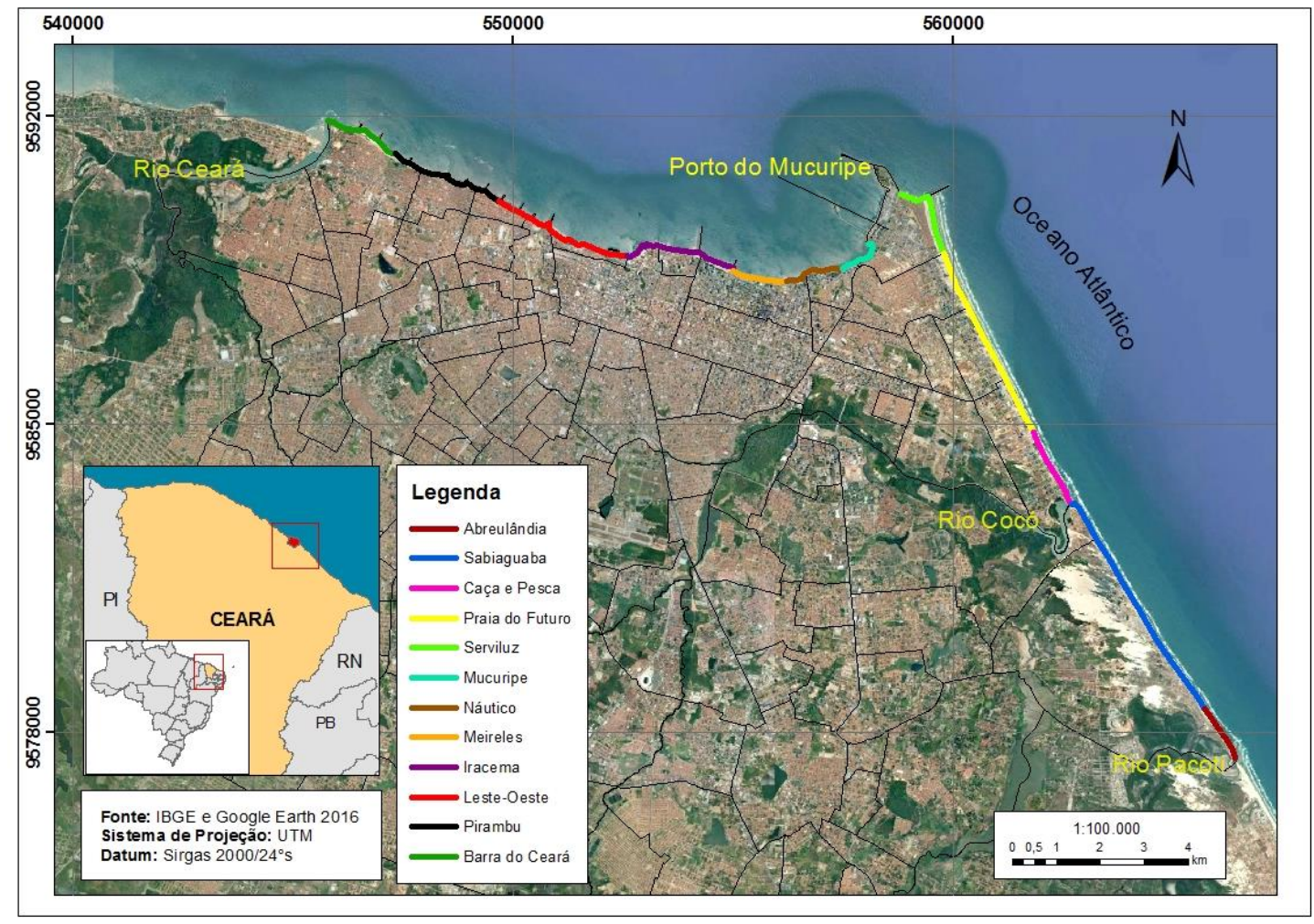

Figura 1 - Segmentação das praias urbanas da cidade de Fortaleza - Ceará. 
Para efeito de delimitação espacial e de identificação do geoambiente foi considerada uma faixa de $800 \mathrm{~m}$ limitando a zona costeira a partir da cota batimétrica de $-6 \mathrm{~m}$ e limitando-se, continente a dentro, ao campo dunas, conforme proposto por LIMA et al. (2016). Tendo como base a metodologia aplicada na Avaliação Ecossistêmica do Milênio (MEA, 2003), formulada entre 2001 e 2005, foi possível valorar qualitativamente os serviços ecossistêmicos oferecidos pela cidade de Fortaleza.

Os serviços ecossistêmicos foram agrupados de acordo com a proposta de MEA (2003), em que os serviços podem ser de provisão, regulação, suporte e culturais. Nesta pesquisa trabalhamos a partir da avaliação conjunta dos serviços de regulação e suporte, sendo as três classes: i) serviços de regulação e/ou suporte, que incluem os serviços de retenção natural de sedimentos, recarga de aquíferos, controle e estocagem de água, assimilação e reciclagem de poluentes, dissipação da energia das ondas, proteção natural na zona de ante-praia e pós-praia, refúgio e/ou berçário marinho, terrestre ou transicional; ii) Serviços de provisão, incluindo os serviços de produção natural de alimentos, produção de alimentos em áreas cultivadas, recursos hídricos, recursos ornamentais, recursos genéticos; iii) serviços de informação e cultura, incluindo os serviços de ecoturismo, turismo histórico/cultural, recreação e lazer, atratividade cênica. A partir desta categorização foram atribuídos critérios para valoração dos serviços, que varia de baixo (1), médio (2) e alto (3) (SANTOS e SILVA, 2012).

\section{Resultados e Discussões}

Capital do estado do Ceará, Fortaleza se destaca pela intensiva intervenção antrópica em diversos trechos de seu litoral, onde as atividades econômicas e demanda por recursos naturais, acompanhadas do processo de urbanização contínua, têm conduzindo à degradação ambiental de seus ecossistemas litorâneos, que são fundamentais ao desenvolvimento econômico da cidade, principalmente para o setor turístico, assim como para o bem-estar da população que se beneficia dos serviços ecossistêmicos prestados.

A faixa litorânea da cidade apresenta intensidades distintas quanto aos tipos de usos e ocupações. O litoral SE/NO da cidade é o menos urbanizado, o que reflete na sua boa qualidade ambiental, diferente do que se observa no litoral L/O, que é massivamente ocupada com presença de estruturas edificadas ao longo de toda sua linha de costa, comprometendo a disponibilidade de serviços ecossistêmicos. A tabela I apresenta os resultados da valoração qualitativa das doze praias do litoral de Fortaleza. A Praia da Sabiaguaba apresentou o maior escore dentre todas as demais, chegando ao total de 46, enquanto que a Praia do Mucuripe e Praia de |Iracema apresentaram os menores valores, ambas, 26 escores. 
Tabela I - Valores associados aos serviços ecossistêmicos oferecidos pelas praias da cidade de Fortaleza. (Adaptado de SANTOS e SILVA, 2012).

\begin{tabular}{|c|c|c|c|c|c|c|c|c|c|c|c|c|}
\hline \multirow{3}{*}{\begin{tabular}{|c|} 
SERVIÇOS ECOSSISTÊMICOS \\
SERVIÇOS DE REGULAÇÃO E/OU \\
SUPORTE \\
\end{tabular}} & \multicolumn{12}{|c|}{$\begin{array}{l}\text { ÍNDICES ATRIBUIDOS AOS SERVIÇOS } \\
\text { AVALIADOS }\end{array}$} \\
\hline & \multicolumn{5}{|c|}{ SE/NO } & \multicolumn{7}{|c|}{$\mathrm{L} / \mathrm{O}$} \\
\hline & $\mathrm{AB}$ & SA & $\mathrm{CP}$ & PF & $\mathrm{S}$ & MU & $\mathrm{N}$ & M & I & LO & $\mathrm{P}$ & $\mathrm{BC}$ \\
\hline Retenção Natural de Sedimentos & 3 & 3 & 3 & 3 & 2 & 2 & 2 & 2 & 2 & 2 & 2 & 2 \\
\hline Recarga de Aquíferos & 1 & 3 & 1 & 2 & 1 & 1 & 1 & 1 & 1 & 1 & 1 & 1 \\
\hline Controle e Estocagem de Água & 3 & 2 & 2 & 1 & 1 & 1 & 1 & 1 & 1 & 1 & 1 & 1 \\
\hline Assimilação e Reciclagem de Poluentes & 3 & 2 & 2 & 1 & 1 & 1 & 1 & 1 & 1 & 1 & 1 & 1 \\
\hline Dissipação da Energia das Ondas & 3 & 3 & 3 & 3 & 3 & 1 & 1 & 1 & 2 & 3 & 3 & 3 \\
\hline Proteção Natural na Zona de Ante-praia & 1 & 2 & 1 & 1 & 1 & 2 & 3 & 2 & 1 & 2 & 2 & 2 \\
\hline Proteção Natural na Zona de Pós-praia & 2 & 3 & 1 & 2 & 1 & 1 & 1 & 1 & 1 & 1 & 1 & 1 \\
\hline Refúgio e/ou Berçário Marinho & 2 & 2 & 2 & 2 & 2 & 1 & 1 & 1 & 1 & 1 & 1 & 1 \\
\hline Refúgio e/ou Berçário Terrestre ou Transicional & 3 & 3 & 3 & 3 & 2 & 1 & 1 & 1 & 1 & 1 & 1 & 1 \\
\hline SERVIÇOS DE PROVISÃO & $\mathrm{AB}$ & SA & $\mathrm{CP}$ & $\mathrm{PF}$ & $S$ & MU & $\mathrm{N}$ & M & PI & LO & $\mathrm{P}$ & $\mathrm{BC}$ \\
\hline Produção Natura & 3 & 3 & 3 & 2 & 2 & 2 & 2 & 2 & 2 & 2 & 2 & 2 \\
\hline Produção de Alimentos em Áreas Cultivadas & 1 & 1 & 3 & 3 & 1 & 1 & 1 & 1 & 1 & 1 & 2 & 2 \\
\hline Recursos Hídricos & 2 & 3 & 2 & 1 & 1 & 1 & 1 & 1 & 1 & 1 & 1 & 1 \\
\hline Recursos Ornamentais & 2 & 3 & 2 & 2 & 1 & 2 & 2 & 1 & 1 & 2 & 2 & 2 \\
\hline Recursos Genéticos & 2 & 3 & 2 & 2 & 2 & 2 & 2 & 2 & 2 & 2 & 2 & 2 \\
\hline SERVIÇOS DE INFORMAÇÃO E CULTURA & $\mathrm{AB}$ & SA & $\mathrm{CP}$ & $\mathrm{PF}$ & $S$ & MU & $\mathrm{N}$ & M & PI & LO & $\mathrm{P}$ & $\mathrm{BC}$ \\
\hline Ecoturismo & 3 & 3 & 3 & 2 & 2 & 2 & 2 & 2 & 2 & 2 & 2 & 2 \\
\hline Turismo Histórico/Cultural & 1 & 1 & 2 & 2 & 3 & 3 & 3 & 3 & 3 & 3 & 2 & 3 \\
\hline Recreação e Lazer & 3 & 3 & 3 & 3 & 1 & 2 & 2 & 2 & 2 & 1 & 1 & 2 \\
\hline Atratividade Cênica & 2 & 3 & 1 & 1 & 1 & 1 & 1 & 1 & 1 & 1 & 1 & 1 \\
\hline TOTAL & 40 & 46 & 39 & 36 & 29 & 27 & 29 & 26 & 26 & 28 & 28 & 30 \\
\hline
\end{tabular}

AB: Abreulândia; SA: Sabiaguaba; CP: Caça e Pesca; PF: Praia do Futuro; S: Serviluz; MU: Mucuripe; N: Náutico; M: Meireles; I: Iracema; LO: Leste-Oeste; P: Pirambu; BC: Barra do Ceará.

O Segmento SE/NO do litoral de Fortaleza apresentou as melhores condições de qualidade ambiental dos ecossistemas, refletindo diretamente na provisão de serviços ecossistêmicos, de modo que as praias deste segmento apresentaram os melhores valores com destaque para praia da Sabiaguaba, onde está presente o Parque Natural Municipal das Dunas de Sabiaguaba e a Área de Proteção Ambiental (APA) de Sabiaguaba, bastante aproveitada para realização de trilhas ecológicas, ou seja, serviços de ecoturismo e apresentando grande atratividade cénica. Além de fornecer outros serviços importantes como produção natural de alimentos e recursos hídricos. As praias Abreulândia, Praia do Futuro e Caça e Pesca se 
destacam no fornecimento de serviços de recreação e lazer devido à boa qualidade ambiental, diferente do que se observou na praia do Serviluz, onde o uso é mais comunitário.

As praias do litoral L/O apresentaram os piores valores dos serviços ecossistêmicos não chegando a atingir mais que 30 escores, o que pode ser justificado pelo intenso adensamento urbano, além de inúmeras infraestruturas (e.g. porto, indústrias, hotéis e obras costeiras) que contribuem para a artificialização da linha de costa, comprometendo a qualidade ambiental e contribuindo para diminuição dos serviços ecossistêmicos desse trecho do litoral. Dentre os serviços que despontam nesse segmento foi possível observar que os culturais foram os que obtiveram maior média de escores, pois trata-se da região turística da cidade, onde estão localizados os principais marcos da história da cidade.

\section{Considerações finais}

Verificou-se que grande parte do litoral se encontra artificializado por obras de contenção costeira e infraestruturas urbanas implicando negativamente na provisão de serviços ecossistêmicos, além de que a demanda populacional vem ultrapassando os limites de fornecimento de serviços prestados pelos ecossistemas. Deste modo, se evidencia a necessidade de aplicação de medidas que garantam a conservação dos ecossistemas litorâneos, tendo em vista a grande demanda populacional impulsionada, especialmente, pelo turismo nas últimas duas décadas.

\section{Agradecimentos}

À FUNCAP pela concessão da bolsa de iniciação científica e ao laboratório de Geologia e Geomorfologia Costeira e Oceânica (LGCO) da UECE, pela infraestrutura e apoio na realização do trabalho.

\section{REFERÊNCIAS}

ANDRADE, D.C.; ROMEIRO, A.R. Serviços ecossistêmicos e sua importância para o sistema econômico e o bem-estar humano. Campinas: IE/UNICAMP, 155 p., 2009.

LIMA, I. F. P.; MONTEIRO, N. V. A.; BENDO, A. R. R.; ALVES, J. W. O. ; PAULA, D. P. Avaliação dos serviços ecossistêmicos nas praias dos municípios de Fortaleza e Caucaia, Ceará, Brasil. In: II Congresso Ibero Americano de Gestão Integrada de Áreas Litorais, 2016, Florianópolis. Anais do II Congresso Ibero Americano de Gestão Integrada de Áreas Litorais. Florianópolis: UFSC, 2016.

MEA - MILLENNIUM ECOSYSTEM ASSESSMENT. Ecosystem and Human Well-Being: a framework for assessment. Washington, DC: Island Press. 2003. 


\begin{tabular}{|c|c|}
\hline $\begin{array}{l}\text { XVII Simpósio Brasileiro } \\
\text { de Geografia Fisica Aplicada } \\
\end{array}$ & $\begin{array}{l}\text { OS DESAFIOS DA GEOGRAFIA FÍSICA NA FRONTEIRA DO CONHECIMENTO } \\
\text { Instituto de Geociências - Unicamp }\end{array}$ \\
\hline $\begin{array}{l}\text { I Congresso Nacional } \\
\text { de Geografia Física }\end{array}$ & $\begin{array}{l}\text { Campinas - SP } \\
28 \text { de Junho à } 02 \text { de Julho de } 2017\end{array}$ \\
\hline
\end{tabular}

SANTOS, Rodrigo C.; SILVA, Iracema R. Serviços ecossistêmicos oferecidos pelas praias do município de Camaçari, litoral norte do estado da Bahia, Brasil. Cadernos de Geociências, Salvador, v. 9, n. 1, p. 47 - 56, maio 2012. 